[Agr. Biol. Chem., Vol. 32, No. 4, p. 522 524, 1968]

\title{
$\alpha$-Isopropylmalic Acid Accumulation by Leucine-requiring Yeast Mutants
}

\author{
By Toshiyuki SAI \\ Tokyo Branch of the Suita Laboratory, Brewing Science Research Institute* \\ Received September 21, 1967
}

Since the discovery of $\alpha$-isopropylmalic acid ( $\beta$-carboxy- $\beta$-hydroxyisocaproic acid) as a precursor for the leucine biosynthesis in Torulopsis utilis, " it has been reported by a number of investigators that the acid was produced as a metabolic product by some strains of bacteria and molds which require leucine for growth. ${ }^{2 \sim 51}$ The occurrence of this acid in higher plants has also been reported..$^{6-81}$

Recently, Strassman and $\mathrm{Ceci}^{91}$ presented a detailed report on the enzymatic formation of $\alpha$-isopropylmalic acid ( $\alpha$-isopropylmalate synthetase) in the cell-free preparations of baker's yeast. However, the accumulation of $\alpha$-isopropylmalic acid as a metabolic product of leucine-requiring yeast mutants (auxotrophs) has not yet been reported.

* c/o Central Research Laboratories, Asahi Breweries Ltd., Sumida-ku, Tokyo.

1) M. Strassman, L. A. Locke, A.J. Thomas and S. Weinhouse, J. Am. Chem. Soc., 78, 1599 (1956); Science, 121, 303 (1955).

2) C. Jungwirth, P. Margolin, H. E. Umbarger and S. R. Gross, Biochem. Biophys. Res. Communs., 5, 435 (1961).

3) W. R. Martin, W. H. Coleman, N. E. Wideburg, R. Cantrell, M. Jackson and F.W. Denison, Jr, Biochem. Biophys. Acta, 62, 165 (1962).

4) J.M. Calvo, M.G. Kalyanpur and C.M. Stevens, Biochemistry, 1, 1157 (1962).

5) C. Jungwirth, S. R. Gross, P. Margolin and H. E. Umbarger, ibid., 2, 1 (1963).

6) G.W. Butler and L. Shen, Biochem. Biophys. Acta, 71, 456 (1963).

7) A. Oaks, ibid, 111, 79 (1965).

8) T. Fukuzumi, H. Takahara, H. Kaneko and I. Onishi, Nippon Nogeikagaku Kaishi, 39, 204 (1965). 9) M. Strassman and L. N. Ceci, J. Biol. Chem., 238, 2445 (1963).
During the courses of our study on citramalate formation by various yeast strains, ${ }^{10,11}$ it was incidentally found that a considerable amount of $\alpha$-isopropylmalic acid was accumulated in the culture medium of leucineless mutants of Saccharomyces cerevisiae. The present paper briefly deals with the isolation and identification of $\alpha$-isopropylmalic acid from the culture fluid of leucine-less yeast mutants.

A leucine-less mutant strain C1461-4D was statically grown for 10 days at $25^{\circ} \mathrm{C}$ in a chemically defined medium ${ }^{10}$ supplemented with a small amount of L-leucine $(10 \mathrm{mg} / \mathrm{l}$ of medium). The culture medium from which yeast cells were removed by centrifugation was acidified to $\mathrm{pH} 2.0$ with sulfuric acid. The organic acids in the acidified medium were then extracted with ether for $72 \mathrm{hr}$ using a liquid-liquid type extractor. The ether extract was then chromatographed on a silicic acid column $(1.0 \times 30 \mathrm{~cm})$ as described previously, ${ }^{101}$ and the chromatogram as shown in Fig. 1 was obtained. An acid corresponding to $\alpha$-isopropylmalic acid was predominant, constituting $56 \%$ of the total amount of the acids produced by leucine-less mutant strain C1461-4D. Chromatography of the ether extracts was repeated to collect the acid fraction corresponding to $\alpha$-isopropylmalic

10) T. Sai and M. Amaha, J. Gen. Appl. Microbiol., 1. 355 (1965).

11) T. Sai and M. Amaha, ibid., 13, 15 (1967). 


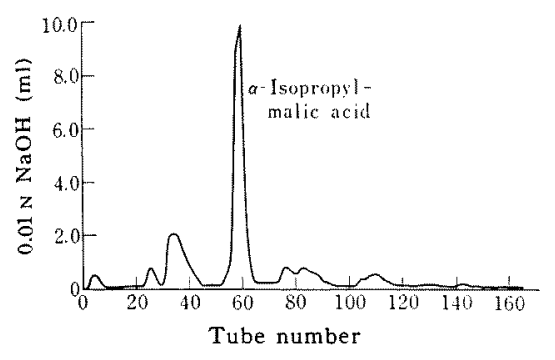

FIG. 1. Silicic Acid Column Chromatogram of the Organic Acids Produced by a Leucine-less Mutant Strain (C1461-4D) of Saccharomyces cerevisiae.

An ether-extract corresponding to $100 \mathrm{ml}$ of culture fluid was applied.

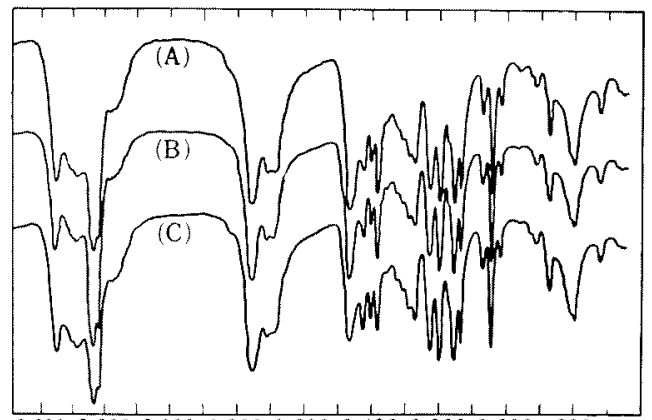

$3,6002,8002,0001,8001,600 \quad 1,4001,2001,000800$

$\mathrm{cm}^{-1}$

FIG. 2. Infrared Spectra of Authentic DL- $\alpha$-Isopropylmalic Acid and the Isolated Acids (in Nujol).

Curve A: Authentic DL- $\alpha$-isopropylmalic acid. Curve B: Acid produced by a mutant strain C1382-11D requiring both leucine and histidine.

Curve C: Acid produced by a mutant strain C1461-4D requiring leucine.

acid using a silicic acid column 1.630 $\mathrm{cm})$. The acid fraction was evaporated to dryness under reduced pressure at $50 \sim 60^{\circ} \mathrm{C}$, and the residue was extracted several times with hot ethyl acetate. The extract, decolorized with charcoal, was concentrated to a small volume to which ligroin was added to be a turbid solution. After allowed to stand for $2 \sim 3 \mathrm{hr}$ at $5^{\circ} \mathrm{C}$, the acid was obtained in a crystalline form. The acid was recrystallized to constant melting point by the same procedure.
The acid showed only one spot corresponding to authentic DL- $\alpha$-isopropylmalic acid on paper chromatography, using four different solvent systems: $R f$ values were 0.85 , (nbutanol-acetic acid-water, 52:14:34); 0.74, (phenol-formic acid-water, 75:1:25); 0.85, ( $n$ butanol-formic acid-water, 4:1.5:1); 0.39 , (cellosolve conc, ammonia-water, 80:5:15). The physical properties of the isolated acid were found to be: $\mathrm{mp} 169^{\circ} \mathrm{C},[\alpha]_{10}^{20}-19.6^{\circ}(c=5.0$ methanol), $-19.6^{\circ}(c=2.5$ in water $),-1255^{\circ}$ in $(c=0.2$ in the presence of excess ammonium molybdate $\left.{ }^{121}\right)$. Found: $\mathrm{C}, 47.43 ; \mathrm{H}, 6.86$. Calcd. for $\mathrm{C}_{7} \mathrm{H}_{12} \mathrm{O}_{5}: \mathrm{C}, 47.72 ; \mathrm{H}, 6.87 \%$. The infrared spectrum of the isolated acid was identical with that of authentic DL- $\alpha$-isopropylmalic acid as shown in Fig. 2.

An acid corresponding to $\alpha$-isopropylmalic acid, which was produced by a leucine and histidine-requiring mutant of Saccharomyces cerevisiae strain C1382-11D, was also separated and crystallized by the same procedure. The isolated acid showed $\mathrm{mp} 170^{\circ} \mathrm{C},[\alpha]_{\mathrm{D}}^{30}-20.0^{\circ}$ $(c=2.5$ in methanol), and an identical infrared spectrum to that of authentic DL- $\alpha$-isopropylmalic acid (Fig. 2). Thus, it is evident that the acid accumulated by the two leucinerequiring mutants $\mathrm{C} 1461-4 \mathrm{D}$ and $\mathrm{Cl} 382-11 \mathrm{D}$ was (-)- $\alpha$-isopropylmalic acid.

Eight leucine-requiring strains of Saccharomyces cerevisiae, including multiple mutants requiring other amino acids and/or bases besides leucine, were then compared for the ability to accumulate $\alpha$-isopropylmalic acid. In this experiment, each strain was statically grown for 6 days at $25^{\circ} \mathrm{C}$ in a $100-\mathrm{ml}$ Erlenmeyer flask containing $50 \mathrm{ml}$ of medium supplemented by the addition of leucine and other amino acids and/or bases $(10 \mathrm{mg} / 1$, each) according to the requirements of each strain. The culture fluids from which cells were removed by centrifugation were passed through a Dowex-1 2 column (acetate form, 1.0 30

12) H. A. Krebs and L. V. Eggleston, Biochem. J., 37, 334 (1943). 
$\mathrm{cm}$ ) and the eluted fraction corresponding to $\alpha$-isopropylmalic acid was iodometrically determined from the amount of methyl ketone compound formed upon permanganate oxidation. These procedures were essentially the same as those employed for citramalate determination in the previous paper ${ }^{11}$ except that $100 \mathrm{ml}$ of the first eluate was discarded and $200 \mathrm{ml}$ of the next eluate $(2.5 \mathrm{~N}$ acetic acid) was collected. The methyl ketone compound, which is formed from the acid upon permanganate oxidation and which reacts with iodine in alkaline solution, was confirmed to be methyl isopropyl ketone from the retention time of gas-liquid chromatography. The retention time of this methyl ketone compound was identical with that formed from authentic

TABLE I. ACCUMULATION OF $a$-ISOPROPYLMALIC ACID BY LEUCINE-REQUIRING MUTANT STRAINS of Saccharomyces cerevisiae
Strain Requirement

Ci $1461-4 \mathrm{D} *$ leucine

Cl461-10C* leucine

C1462-5B leucine

C1382-11D* leucine and histidine

$\mathrm{C} 814-45 \mathrm{C}^{*}$ leucine, histidine and uracil

C7-2A leucine, lysine, methionine, tryptophan and adenine

$\alpha$-Isopropylmalic acid formed $(\mathrm{mg} / 100 \mathrm{ml}$ of medium)

$\mathrm{S} 2583 \mathrm{D}$ leucine, tryptophan, histidine, valine, isoleucine and adenine leucine, lysine, tryptophan,

$\$ 2582 B$
74.7

64.2

36.6

41.9

32.6

13.6

24.4

38.4
The basal medium used was Yeast-Nitrogen-Base (Difco) plus glucose 5\%; each of the amino acids and bases required was added at the concentration of $10 \mathrm{mg}$ per litre of medium.

* These four mutant strains are presumed to be deficient in $\beta$-carboxy- $\alpha$-hydroxyisocaproic acid dehydrogenase, based on the description of R.C. von Borstel ${ }^{13}$ and the genetic analysis of CiL61-4D.14)

13) R. C. von Borstel, Microbial Genetics Bulletin, Yeast Genetics Supplement to No. 25, 1 (1966).

14) T. Takahashi, Private communication.
DL- $\alpha$-isopropylmalic acid. As shown in Table I, all the eight leucine-requiring strains accumulated $\alpha$-isopropylmalic acid in the culture media, though the amount of the acid varied from 13 to $75 \mathrm{mg}$ per $100 \mathrm{ml}$ of medium. On the other hand, it was found that none of the ten leucine-independent auxotrophic mutants (Saccharomyces cerevisiae) requiring other amino acids for growth could accumulate $\alpha$-isopropylmalate in the medium. These facts clearly show that the $\alpha$-isopropylmalic acid accumulation is correlated to the existence of a metabolic block in leucine biosynthesis. It seems that $\alpha$-isopropylmalate synthetase, a condensing enzyme involved in the first step, is more active than the other intermediate enzymes of leucine biosynthesis under the leucine-insufficient condition.

The amount of $\alpha$-isopropylmalic acid accumulated by the leucine-less mutant strain C1461-4D could be increased to $116 \mathrm{mg} / 100 \mathrm{ml}$ of medium, when calcium carbonate $(3 \circ)$ was added to the medium. It was also found, however, that accumulation of $\alpha$-isopropylmalate by the leucine-less mutant was almost completely inhibited by a higher concentration of L-leucine $(500 \mathrm{mg} / \mathrm{l}$ of medium), indicating that the condensing enzyme ( $\alpha$-isopropylmalate synthetase) is also effectively regulated by end-product inhibition, a feed-back mechanism.

The author is indebted to Mr. M. Nakajima, the President, and to Mr. S. Takayanagi, the Managing Director, of Asahi Breweries Ltd., for the permission to publish this work. Thanks are also due to Dr. M. Amaha, Central Research Laboratories, Asahi Breweries Ltd., for his many helpful suggestions and advices. The yeast mutant strains employed in this study were generously supplied by Dr. T. Takahashi, Suita Laboratory of the Brewing Science Research Institute, and an authentic sample of $\mathrm{DL}-\alpha$-isopropylmalic acid by Dr. H. Kaneko, Central Research Institute, Japan Monopoly Corporation. 